\title{
Implications of COVID-19 Regulations for People With Visual and Intellectual Disabilities: Lessons to Learn From Visiting Restrictions
}

\author{
Aline K. Honingh* (D), Angelique Koelewijn ${ }^{\dagger}$, Bert Veneberg ${ }^{\dagger}$ (D), Francis ter Horst ${ }^{\dagger}$, and Paula S. Sterkenburg ${ }^{\star}$, ID $^{\circ}$ \\ ${ }^{\star}$ Department of Clinical Child and Family Studies, Vrije Universiteit Amsterdam, Amsterdam, The Netherlands; and ${ }^{\dagger}$ Bartiméus, \\ Doorn, The Netherlands
}

\begin{abstract}
Background: Due to the COVID-19 pandemic, governments of many countries announced regulations to prevent the virus from spreading. For people with a disability living in a sheltered care facility in the Netherlands, this meant that they were not able to receive any visitors for almost 3 months.

Aim: This study examines how people with an intellectual and visual disability and their families experienced the period in which it was mandated not to have any physical contact. The aim is to examine the experiences of this target group and gain insight in the way measures were taken in order to be able to advise care organizations about adequate care with respect to possible restrictive measures in the future.

Methods: In-depth interviews were conducted with two groups of people: (1) fourteen people with an intellectual and visual disability, living in sheltered care facilities and (2) twelve people being relatives of residents of these same sheltered care facilities. In the interviews, the participants were questioned about their experiences with respect to the adjusted visiting regulations and with respect to the relation with their family during this period. A thematic analysis was performed first separately and then combined. Results and Discussion: A number of themes resulted from the analysis that were related to (1) the instructed regulations of the sheltered care facilities and the government; (2) the relation with family and friends; and (3) the consequences of COVID-19 and the regulations. Both relatives and residents were understanding of the difficult situation, but also expressed criticism about the chosen regulations, the communication thereof, and the practical implementation. Both groups have experienced the interruption of close contact as emotional and difficult. However, also positive consequences of the restrictions due to COVID-19 were mentioned. The results provide a list of recommendations for sheltered care facilities.
\end{abstract}

Keywords: COVID-19, experiences, intellectual disability, policy, visiting restrictions, visual impairment

\section{Introduction}

The COVID-19 pandemic has an enormous impact on people's lives, worldwide. The COVID-19 measures that have been proclaimed by governments of several countries include regulations about keeping distance from all people excluding one's own family, staying at home, and canceling social events. For people with disabilities these regulations have even more impact: in many cases they could not see their family for a considerable period of time. In the Netherlands there was a socalled lockdown period from March until May 2020, following the regulations of the government (Rijksoverheid, 2020). Most care organizations for people with disabilities responded by closing their shared care homes for visitors including family,

Received December 27, 2020; accepted September 27, 2021

Correspondence: Paula S. Sterkenburg, Bartiméus, Oude

Arnhemsebovenweg 3a, 3941XM, Doorn, The Netherlands. Tel: +31 (0)

343526543 or +31 (0) 205988890; E-mail: p.s.sterkenburg@vu.nl,

psterkenburg@bartimeus.nl following additional national advice from the VGN (Vereniging Gehandicaptenzorg Nederland, 2020a). Most residents could therefore not receive any visitors and only had contact with their daily caregivers during this period. In this study, we examine how people with disabilities and their families have experienced this period and what can be learned from this challenging period.

The quality of life for people with a disability has been investigated in different ways and several models have been proposed (e.g., Maes, Geeraert, \& Van den Bruel, 2000; Schalock, 1996). Schalock and his colleagues have studied the concept of quality of life for many years from several perspectives (Brown, Schalock, \& Brown, 2009; Schalock, 1996; Schalock et al., 2005) and have decomposed the concept of quality of life for people with disabilities into eight universal core domains: (1) emotional well-being (contentment, lack of stress); (2) interpersonal relations (interactions, relationships, supports); 3) material well-being (employment, housing); (4) personal development (education, personal competence); (5) physical well-being (health, activities of daily living, leisure); (6) self-determination

(C) 2021 The Authors. Journal of Policy and Practice in Intellectual Disabilities published by International Association for the Scientific Study of Intellectual and Developmental Disabilities and Wiley Periodicals, LLC.

This is an open access article under the terms of the Creative Commons Attribution-NonCommercial License, which permits use, distribution and reproduction in any medium, provided the original work is properly cited and is not used for commercial purposes. 
(autonomy, choices); (7) social inclusion (community integration and participation); and (8) rights (respect, equality, citizenship) (Schalock, Keith, Verdugo, \& Gómez, 2010). From this list, it can directly be inferred that the COVID-19 regulations have disturbed six quality-of-life domains for persons with disabilities: emotional well-being (due to stress), interpersonal relations (no visiting family, no work at the workplace), physical well-being (due to leisure activities that were canceled), self-determination (restrictions in choices to make), social inclusion, and rights (since the regulations for people with a disability do not equal the regulations for other people).

This study is aimed at people with an intellectual disability (ID) who also have a visual disability. This group of people may have suffered from the COVID-19 regulations even more than people with an ID only, since they are used to physical contact to guide and help them. Also, keeping distance is more difficult for people who are blind, since they cannot visually estimate the distance.

Since the start of the COVID-19 pandemic, several studies have been undertaken on the consequences of the disease and of the (contact limiting) measures, also with respect to people with disabilities. It has been argued that people with ID are especially vulnerable to the effects of the pandemic (Courtenay \& Perera, 2020) and also a high impact from the COVID-19 pandemic is expected on the lives of people with a visual disability (Senjam, 2020). A qualitative study on the experiences of people with a mild ID reported on: missing social contact, a changed daily life, and difficulties to understand the preventative measures (Embregts et al., 2020). A study on the effect of the COVID-19 pandemic on mental health found a high level of mental health problems among carers of people with ID (Willner et al., 2020).

This study investigates how people with an ID and visual disability and their families experienced the mandated COVID-19 lockdown period during which there was no physical contact with family and friends. Specific questions are: What is the impact of this period where no visitors were allowed at sheltered care facilities? How did residents and relatives experience this period? What is the impact of the visiting restrictions on their relationship? What can care providing organizations learn from their wishes and needs?

\section{Methods}

\section{Design}

In this research, the experiences of persons with a visual disability and ID and their relatives are investigated by using a qualitative exploratory design. In-depth interviews were conducted by an inclusive research team.

\section{Participants}

Two groups of participants were selected for this study. The first group consists of residents of one of the two national Dutch care facilities for people with a visual disability. The focus of this study is on the group of people with both a visual disability and ID. Bartiméus provides sheltered care facility homes for about 571 persons living individually or in groups of up to eight persons.
The group of residents that were interviewed consists of 14 persons (nine males, five females) with a visual disability (ranging from a visual impairment to blindness) and a mild to moderate ID. The ages of the residents range from 23 years to 70 years with an average of 45.7 years. They all live in sheltered care facility homes in three different cities of the Netherlands, where they receive support with several tasks. These residents either work in a sheltered workplace or attend a structured daytime activity center.

The second group of participants consists of 12 relatives of residents of sheltered care facility homes (not equaling the residents from the first group). These relatives are the father, mother, brother, or sister of a person with a visual disability and ID living in sheltered care facility homes. They are relatives of persons with an ID ranging from mild to severe and visual disabilities ranging from visual impairment to blind; one person is deaf-blind. Their ages range from 21 to 62 years, with an average of 45.9 years.

The inclusion criteria for group 1 were as follows. The participants had to live in a sheltered care facility, having a visual disability and ID, and had to be able to express themselves verbally. The last criterion meant that people with a severe ID could not participate in group 1 . In order to get a balanced outcome of the experiences of all people with disabilities living in a care facility at Bartiméus, in group 2, the focus was more on relatives of people with a severe ID. In order to get a representative mix of both groups (clients and relatives), several categories had to be represented in a balanced way. These categories include: locations of Bartiméus; degree of visual disability and ID; ages (of clients and relatives); relation client-relative; work or daytime activities for clients; visiting habits (e.g., going home on weekends or not); and applied quarantine or not (because of COVID-19 infection in the sheltered care facility).

A list of clients and relatives was made, such that the total of their attributes was balanced over these categories. These clients and relatives were invited for an interview. One client indicated that he did not want to participate. Two relatives indicated that they could not participate because of other activities or obligations. Participant numbers were assigned randomly.

\section{Procedure}

The proposal for this study was discussed with and approved by the management team, client committee, and COVID-19 team. The ethical team of Bartiméus granted permission (reference: Ma 29-6-2020 11:16) for the study that was conducted according to the Ethical Principles for Medical Research Involving Human Subjects of the World Medical Association declaration of Helsinki (World Medical Association, 2013).

Before the interview, all eligible participants were given written and verbal information about the study. The purpose of the interviews and the instructions for the participants were written by $\mathrm{BV}$ who has extensive experience in enhancing communication with the target group. Written informed consent was obtained before the start of the interviews.

In order to be able to capture the experiences of both residents and relatives during the mandated 3-month lockdown period from March to May 2020, it was important to interview them as soon as possible after this period. To this end, a team of five professionals 
of Bartiméus collaborated with two professionals from Altuïtion, a company specialized in customer experience. All interviewers were trained in customer experience research by Altuition. The interviews were held in the period from June to August 2020.

The semi-structured interviews with the residents were held by an interview team employed by the participating organization and consisted of five trained professionals with and without a visual impairment. Thus, it was an inclusive research team, as recommended by, for example, Nind (2017). Data saturation was reached after interviewing 13 residents, after which one extra interview was conducted. The semi-structured interviews with the relatives were conducted by a trained and experienced person from Altuition. They developed and used several elicitation techniques to gain insight in perceptions (thoughts and feelings) of people about specified research questions (Van Slooten, Veldhoen, Achthoven, van Rensch, \& van Ratingen, 2018), inspired by the Zaltman metaphor elicitation technique (ZMET). ZMET is a technique that elicits both conscious and unconscious thoughts and feelings by exploring people's metaphoric expressions (Zaltman, 1996). Data saturation was reached after interviewing 11 relatives, after which one extra interview was conducted.

The duration of the interviews had a minimum of 1 hour and a maximum of 2 hours, with a mean duration of 88 minutes (residents) and 99 minutes (relatives). Interviews were sound recorded and later transcribed by independent researchers. The transcriptions were checked by the interviewers.

Participants of the two groups (residents and relatives) were asked to think about the period in which the adjusted visiting scheme was valid. They were asked to bring images that expressed their thoughts and feelings with respect to the visiting regulations and with respect to their relation with their family during this period. During the interviews, participants were first asked to describe the image literally and then to describe their thoughts and feelings that are associated with it. Using the laddering technique (e.g., Miles \& Rowe, 2004; Reynolds \& Gutman, 1988), a questioning technique through which a hierarchy of concepts can be derived, the interviewers tried to interpret the thoughts and feelings of the participants. This is done by asking variants of the question "Why is that important to you?", which could include "How does that make you feel?" or "What does that do for you?". The response to that question is again used as a probe for a variant of the same question (Reynolds \& Phillips, 2009). This way of questioning continues until one ends up with a complete "ladder": the emotions and motivations belonging to a specific topic. All topics that come up during the interview are handled in this way.

The interviews, transcriptions, and data analysis were performed in Dutch. The results have been translated to English afterward. There was agreement on the translation by all authors. In the translation of the quotes from the interviews, the aim was to stay as close as possible to the words that were spoken without deviating from the meaning of a sentence.

\section{Data Analysis}

The transcribed interviews were analyzed in two phases. First, the interviews with the residents were analyzed separately from the interviews with the relatives. The interviews with the residents were analyzed by the interview team from Bartiméus together with one extra researcher and the interviews with the relatives were analyzed by two researchers from Altuïtion. In the second stage, the themes of the residents were compared to the themes of the relatives to identify overarching themes. Recommendations were based on the full set of themes, where the topics that were found in both groups (residents and relatives) were emphasized most.

In the first phase, a thematic analysis was performed (Braun \& Clarke, 2006) in order to be able to identify themes within the interviews. To this end, first of all, interviews were repeatedly read for familiarization. For each interview, topics were notated together with its ladder (the emotions and motivations belonging to the topic). Quotes from the interview belonging to these topics were extracted as well. For each topic that was found, the number of occurrences was counted among all interviews in the group of clients/relatives. Thereafter, the topics were ordered from most to least important, based on the number of occurrences in the interviews. In a focus group session with the interview team and one extra researcher, the topics were discussed, from most to least important. Thereafter, the topics were grouped, based on their relationship and overlap with other topics and on the number of occurrences. These groups of topics were discussed until consensus was reached. In this way, a number of themes arose, supported by topics and quotes from the interviews. Each theme was supported by at least three interviews. The themes were presented to the participants in feedback sessions. Separate feedback sessions were organized for residents and relatives. During the feedback sessions of approximately 1 hour, which were organized in small groups of two to four persons, the themes were confirmed. No additional information was added.

In the second phase of the analyses, the resulting themes from the clients' interviews were compared with the themes of the relatives' interviews and overarching themes were identified. Based on corresponding themes from residents and relatives, recommendations were formulated.

\section{Results}

In the group of residents, eight overarching themes were identified and in the group of relatives, seven themes were found (see Table 1). In both groups, participants talked primarily about the regulations made by the care facility (based on the national regulations) in order to reduce the impact of COVID19. Therefore, many themes that were identified are connected to this (four themes in the residents' group, five in the relatives' group). In contrast, there was less attention for aspects relating to relationships and the question whether the relation with relatives had changed during the lockdown period (one theme for each group). Finally, a number of themes were related to the consequences of COVID-19 and the regulations (three themes in the residents' group, one in the relatives' group).

\section{Themes of Residents Concerning Regulations}

Concerning the regulations posed by the care organization which were based on the Dutch governmental COVID-19 measures, residents experienced a sudden change in their daily routine 
TABLE 1

Themes that resulted from the analysis

\begin{tabular}{|c|c|c|}
\hline & Themes - residents & Themes - relatives \\
\hline \multirow[t]{5}{*}{ Regulations } & $\begin{array}{l}\text { A. From one day to } \\
\text { the next, } \\
\text { everything is } \\
\text { different }\end{array}$ & $\begin{array}{l}\text { I. Understanding the } \\
\text { situation and } \\
\text { compliments }\end{array}$ \\
\hline & B. Feeling locked up & $\begin{array}{l}\text { II. Need for extensive } \\
\text { communication }\end{array}$ \\
\hline & $\begin{array}{l}\text { C. Not knowing what } \\
\text { to expect }\end{array}$ & $\begin{array}{l}\text { III. Helplessness } \\
\text { reinforced by } \\
\text { rigidity }\end{array}$ \\
\hline & $\begin{array}{l}\text { D. Differences in } \\
\text { application and }\end{array}$ & $\begin{array}{l}\text { IV. Incomprehension: } \\
\text { double standards }\end{array}$ \\
\hline & $\begin{array}{l}\text { communication of } \\
\text { COVID-19 } \\
\text { measures }\end{array}$ & V. Bending the rules \\
\hline Relations & $\begin{array}{l}\text { E. Contact from a } \\
\text { distance }\end{array}$ & $\begin{array}{l}\text { VI. Alternatives } \\
\text { should be provided }\end{array}$ \\
\hline \multirow[t]{3}{*}{ Consequences } & $\begin{array}{l}\text { F. Fear for COVID- } \\
19\end{array}$ & $\begin{array}{l}\text { VII. Prospect of an } \\
\text { alternative reality }\end{array}$ \\
\hline & $\begin{array}{l}\text { G. The difficulty of } \\
\text { being } 24 / 7 \text { together } \\
\text { with fellow } \\
\text { residents }\end{array}$ & \\
\hline & $\begin{array}{l}\text { H. Living more } \\
\text { relaxed with } \\
\text { positive attention }\end{array}$ & \\
\hline
\end{tabular}

(theme A). From one day to the next, they were not allowed to go to work anymore, they could not do their groceries and their leisure-time activities were canceled. Suddenly everything was different and this was difficult for them to deal with.

Although residents appreciated that the daytime activities were moved to the living group, residents felt being locked up (theme B). Their regular walkways in and to their homes and other facilities were changed to be able to keep the required $1.5 \mathrm{~m}$ distance from each other. Medical appointments were canceled. It was neither allowed to visit family or friends, nor to receive visitors including family. It was not even allowed to leave the neighborhood. If residents wanted groceries, they had to hand over their debit card to the staff.

The residents did not know what to expect (theme C). Nobody could tell them how long these regulations would hold. They could understand that the regulations were important, but it was difficult for them that neither staff nor family could answer their questions about COVID-19.

Residents agreed that the management team of the careorganization had done well introducing the regulations, though differences with respect to application and communication of the rules were noticed (theme D). They were offended by the fact that their family sometimes knew more about the regulations than they did. Furthermore, if something was not allowed according to the official rules, it was still possible to ask for special permission, but it was unclear to the residents how these decisions were made. When the regulations were slowly changing into less strict rules, it was difficult for the residents that the regulations within the care facilities were changing more slowly than the national regulations.

I didn't really know what was happening to me because I... suddenly everything was gone. All of a sudden. Of course I am used to a day of going to work, you come home, you do your things. And suddenly I didn't have that, so my whole daily structure was just gone. (Theme A, resident 3)

So you, you are constantly inside. Well, you have nowhere to go. I used to go to the village every now and then, but well, that is not possible now... Actually, we are stuck within the care facility. (Theme $\mathrm{B}$, resident 10)

I find that quite difficult myself, quite difficult. Especially if you ask them, if you ask anyone, like: 'How long will it take?' That person also says, like: 'Well, I don't know'. That is just hard, difficult foremost. (Theme $\mathrm{C}$, resident 4)

A better communication is necessary... Well, I don't have an example immediately, but one day it was thís rule, while the other day it was thát rule. The regulations sometimes changed. Well, it was either the press conferences that moved too fast or it was here where things moved too slowly. (Theme D, resident 13)

Well, if you send a letter to the legal representatives... I didn't get one, while I am able to understand. I didn't like that and thought: This is also about me. (Theme $\mathrm{D}$, resident 5)

\section{Themes of Residents Concerning Relations}

With respect to social relations and having contact from $a$ distance (theme E), residents focused, besides family, also on friends, colleagues, and support staff. They were proud to find out that they were able to use digital devices for video calling. Sadly, they also lost contact with some friends or colleagues because not everybody wanted or was able to call. Postcards were highly appreciated and most residents listened to news updates to stay in touch with the "outside world." It appeared that technology could partly compensate for the absence of (physical) contact. Besides video calling, a robot-cat and a device for, among others, vocalizing written text were mentioned.

At important moments (birth of cousin, birthday, death) it was especially hard not to be with family. Residents missed an arm around them, for consolation, but also for physical guidance which they need because of their visual impairment. Guidance with walking outside was done with a $1.5 \mathrm{~m}$-long stick, which was a challenge. Guidance with eating was impossible while keeping distance. When receiving visitors was allowed again, this was nice for residents, but also awkward. There was no privacy and it was noisy outside which made it difficult to 
understand each other. Visiting times were very short and strict and residents had the feeling they were being watched to see whether the distance rule was obeyed.

That was sad sometimes. I sometimes cried about that, that I just missed them [...] because none of my family, my brothers, sister-in-law... were allowed to come. (Theme E, resident 5)

But well, I really missed that arm around me all the time. That is a tricky one, because you don't know whether the virus spreads, whether it also spreads via clothing. But well, the arm around me I missed all the time. A piece of security... that people are there for you. (Theme E, resident 13)

\section{Themes of Residents Concerning Consequences}

Concerning the consequences of COVID-19 and the regulations, residents experienced a lot of fear (theme F). They thought about the question: what if I or one of my relatives gets infected by it? These questions have triggered extra questions and worries. One of the worries concerns the question whether and how they will receive care when they get infected. Residents also worried about people who do not obey the rule of keeping distance. This behavior makes them angry and sad.

It was hard for relatives to be with fellow residents all day without having some time off without each other (theme G). There are different opinions, also on the topic of COVID-19 regulations, and not everybody could keep their temper in discussions.

Despite this, residents also experienced positive effects of the regulations (theme $\mathrm{H}$ ). The fact that they did not have to go to work every day was also relaxing and gave a "holiday feeling." There was more time for hobbies and the support staff also had more time to help them or to play a game with them. Moreover, residents had thoughts about the positive effects of COVID-19 for the environment (less pollution) and the society (people being less in a hurry).

Well, you know, you hear so many things. Who is allowed to come [in case of infection], who is not allowed to come? At first I thought: Oh no, that means that our care might be different, that it might be less, or well, that it is... They have reassured me: 'Well, that's not going to happen. If you would have corona, we just keep coming [to care for you], but then we keep our distance.' That reassured me. (Theme $\mathrm{F}$, resident 1 )

Well, because.. Really everything was closed, I found that quite difficult. Then you will respond to others, reacting in a slightly irritated way, which is not really necessary, but it does happen. While you know: the other is having a hard time as well. (Theme G, resident 4)

To mean something for each other, I didn't think that's bad. Otherwise it is all rushing, rushing, hurry, hurry. And not at this time... not all stressed. And also very peaceful. Nice to chat with each other. You don't have to think: 'I have to work'. (Theme H, resident 7)

\section{Themes of Relatives Concerning Regulations}

With respect to the regulations made by the care facility and the Dutch government, relatives had great understanding and sympathy for the situation (theme I). They settled in the situation and had much appreciation for the care-givers. They complimented the care facility on preventing a disaster.

However, relatives also felt insecure and longed for good communication (theme II). They expected and hoped to be informed in layers, from general information about regulations (from the management of the care facility) to more detailed information about consequences in the living group (from the staff working at the care facility home). Ideally, they had also received specific information about the situation of their relative. They were disappointed about the distant and nonempathetic way of communicating and the fact that the residents did not receive tailor-made information.

When the relatives could not visit their loved one at their care facility home, they felt broken-hearted, helpless, locked out, and stressed (theme III). This feeling was reinforced by the rigidity with which the care facility presented the regulations. The relatives wished that the care facility could have been more flexible and creative with the rules for visits, such that the specific disability of the resident and the personal circumstances of the relatives could have been taken into account.

The regulations posed by the care facility were incomprehensible and double standards were noticed, according to the relatives (theme IV). They feared for infection of the residents through staff members since keeping distance is often not possible for support staff. The facts that different locations had different regulations and that some people received privileges were incompatible with the rigid rules they experienced. The relatives would have preferred a transparent policy in which differentiation was possible. Since team managers dealt in different ways with the request for differentiation, relatives felt dependent on the leniency of the concerning team manager.

When the request for differentiation was not granted, some relatives started bending the rules with respect to keeping distance and visiting times (theme $\mathrm{V}$ ). Reasons for doing this were primarily focused on the well-being of the resident. Since relatives were convinced that residents had a bigger risk of getting infected with COVID-19 from the staff than from them, the decision to do this (e.g., to hug each other) was not difficult to make.

I mean, I'd rather think they would be super stressed. I was just amazed that they weren't, because I found it stressful already. So, a big 'well done'. (Theme I, relative 11)

The second [message], that came on March 17 [...] and that was information from a ... also very general. I thought it was very cold, to the extent that 'if you want information, you can [...] visit the [...] website'. Then I thought: well, what are these messages? I mean, we're not toddlers, aren't we? There I was really... yes, I was very indignant about that. (Theme II, relative 2)

That they call me: 'Yes, he can go for a walk for an hour'. But I have a form of rheumatism. Some days I can walk for an hour and other days I cannot. I should not walk in the rain. So they should have called me. (Theme III, relative 10) 
The agreements within the same care facility were also different. In Zeist people were not allowed to sit; they had to go for a walk with their relatives. Here in Doorn you were not allowed to walk with your relative. That's weird. It is good that general rules are made, but then also look at the individual. (Theme IV, relative 6)

But in his room: well, of course we haven't been there for months, but I'm not going to keep one-and-a-half metre distance. That is very strange of course, if you keep this distance while sitting with someone with such a disability. That just doesn't work with him. He likes to sit against you and, well... (Theme $\mathrm{V}$, relative 5)

\section{Themes of Relatives Concerning Relations}

The relatives had a good understanding of the impact that the lockdown period had on their son/daughter/sister/brother. With respect to their relationship, the relatives were in need of spending quality time and wished that the care facility provided alternatives for physical contact (theme VI). They missed seeing, feeling and hugging their loved one and doing activities through which connections can be strengthened and memories can be built. Being physically together was also mentioned as being important in order to truly get a grip on how someone is feeling. For some people, communicating via digital devices was possible, but for others, it was not. The relatives realized that the staff had become their eyes and ears and were very grateful to receive videos, postcards, or phone calls. However, in general, the relatives had hoped for more creativity and possibilities to stay in touch with the residents.

This could also have been Rummikub [a game]... Well, that you don't do it from a distance, that you look for the proximity of people to, in this case, play a board game. By which you also create an activity that strengthens a connection. (Theme VI, relative 3 )

I am walking on eggshells because I am not allowed to touch him. [...] But in any case, the bottom-line for me is that if you want to be together, you want him close to you. That is what it's all about. (Theme VI, relative 12)

\section{Themes of Relatives Concerning Consequences}

As a consequence of COVID-19 and the measures, a number of relatives can see the possibility of doing things differently in the future: the prospect of an alternative reality (theme VII). Because of this period in which visiting was not possible, relatives started reflecting on the past and on the patterns that had emerged. They realized, for example, that their son was more independent than they thought, that their sister was feeling happier since she did not go to work daily, or that the visiting scheme in the past took more energy from themselves than they wished. Some of them used this opportunity to change certain patterns.

That actually gives, I think, a positive experience. Because well, we are both in our seventies and don't have eternal life. We can still visit them now, but it can suddenly change. Then it is also good to know that they feel very good in the care facility. (Theme VII, relative 4)

\section{Recommendations}

Based on the combination of results from relatives and residents, a number of recommendations for care organizations can be made. Some recommendations stem directly from the wishes of the relatives. Other recommendations come from experiences, fears or problems of residents that are expressed here as possible solutions.

Recommendations with respect to the communication with the residents and their relatives are to:

- Communicate in layers: from general to specific, where communication about details in the residential group is done by the caregivers from that specific group.

- Communicate about the policy of differentiation.

- Provide information about measures in the residential group as concretely as possible, by going through different scenarios.

- Communicate empathically.

- Give residents access to the same communication as their relatives, but also provide the residents with additional information that is aimed at people with a visual disability and ID.

Recommendations with respect to regulations are to:

- Apply measures in layers and allow for differentiation based on practical feasibility and the well-being of residents and their relatives.

- Choose feasible measures that will eliminate fear about contamination by staff.

- Take into account the need for quality time and organize alternatives for physical meetings in consultation with relatives.

- Be aware that violation of the rules is caused by a need and can therefore best be dealt with using empathy.

Recommendations with respect to the implementation in practice are to:

- Take the time to talk with residents about COVID-19 and their fears.

- Facilitate the support staff to promote the interests of individual residents (make sure that specific care continues, provide mediation and reflection in case of conflicts and agitation in the house) and inform relatives about this.

- Help residents to use different devices to stay in touch with family, friends and colleagues.

- Facilitate the support staff in their role of "ears and eyes" of the relatives.

- Facilitate the support staff to find creative possibilities of creating quality time for residents and their relatives. 
- Keep evaluating the situation, such that the positive consequences of the regulations can be maintained.

\section{Discussion}

In this study on the experiences of residents of care facility homes and their relatives during the COVID-19 lockdown, it appeared that both groups reflected primarily on the COVID-19 regulations imposed by the care facility. They were understanding of the difficult situation but also expressed criticism. Both groups have experienced the interruption of close contact as emotional and difficult. Despite the negative consequences of COVID-19, also positive experiences have been listed.

A number of aspects from the results appeared to be specific for people with a visual disability. For example, people with a visual disability need a more concrete explanation of what others immediately see, about, for example: What is a mouth mask? How far is $1.5 \mathrm{~m}$ ? Secondly, changing routes to and in buildings has a great impact on the self-reliance of people with visual (and intellectual) disabilities. Furthermore, some residents realized that not all residents in the sheltered care facility home have an equally good understanding of the rules and that they all have a visual disability, which caused stress about how to keep social distance in their home. Finally, people with a visual disability are used to receiving physical help, for example, to hold an arm for guidance while walking. These examples illustrate some additional difficulties that people with a visual disability faced, compared to people with an ID only.

COVID-19 and the adjusted visiting regulations were expected to influence the eight core domains of quality of life as listed by Schalock et al. (2010). Certain consequences of the regulations (e.g., no visiting family, restrictions in choices to make) influence the core domains directly (see Introduction). In addition, the results of our study reveal that disturbance of these domains was clearly felt as well. Residents experienced fear (emotional wellbeing); they missed their family and friends (interpersonal relations); they regretted that certain leisure activities were canceled (physical well-being); they felt locked up within the care facility (self-determination); they felt the unfairness of the regulations for them not equaling the general regulations for all people (social inclusion); and they did not like the fact that they had to hand over their debit card to receive groceries (rights). However, it was found that many residents also experienced positive effects of the regulations, like, for example, having more time for hobbies and feeling more relaxed and less rushed, contributing positively to the domain of physical well-being. Furthermore, the domain of personal development was also influenced positively for a few residents, reflected by the fact that relatives commented on the improved ability of these residents to cope independently. It will be important to examine the long-term effect of COVID-19 on the quality of life for persons with a visual disability and ID.

Comparing our results to results from other studies, some things are worth pointing out. From the three themes "missing social contact," "changed daily life," and "difficulty to understand the preventive measures," found by Embregts et al. (2020), the first two can also be recognized from our analysis of the interviews with residents of the participating care facility. With respect to the preventive measures, however, the residents that participated in our study did not put emphasis on the topic of understanding the measures, but rather focused on the differences and inequality in COVID-19 measures (theme D in Results section). Our finding that relatives experienced stress during the lockdown period resonates with the study of Willner et al. (2020) who found a high level of mental health problems among carers of people with ID.

The Dutch organization for disability care (Vereniging Gehandicaptenzorg Nederland, 2020b) concludes from internal investigations that in future, generic measures should be minimized, because of the diversity in which persons with disabilities are vulnerable for COVID-19. Our study confirms that differentiation is preferred over generic measures and adds that communicating about this is important.

Despite the fact that the relation between residents and relatives was one of the two topics of the interviews of our study, the interviews were more focused on the measures. One can think that it is possible for a relation to change due to visiting restrictions, but not much was said about this. Relatives seem to distinguish between the actual relationship (father/ mother/son/daughter) and the emotional connection experienced. It was mentioned a couple of times that the actual relationship will always remain. In other words: an adjusted visiting scheme has no influence on this. However, the need to be physically together was very strong. As mentioned by Tomova et al. (2020) more research is needed to examine the kind of and amount of positive social interaction that is needed to attune to social needs. In our study it appeared that technology could partly compensate for the absence of physical closeness of important others. However, especially the relatives in our study mentioned explicitly that communication via video calling was not sufficient for them.

In our study, the experiences of both the residents of carefacilities and their relatives were studied and analyzed, in order to be able to view the situation from multiple sides. However, the experiences from the support staff and management are also important to get an even more complete overview of the experiences and needs of people concerned with disability care. It is important to include this in future research as well.

\section{Acknowledgments}

The authors thank all participants (residents and relatives) for their contribution to this research. Furthermore, the authors thank Lars Lommers, Sabine van Wanrooij and two independent researchers from Altuition for their contribution to the collection and analysis of the data, and thank Joyce Schroor for administrative support. Finally, the authors thank the sheltered care organization for opening their doors for this study. This study was funded by ZonMw (reference number: 60-6410098101) and Bartiméus Fund (reference number: P00238).

\section{Conflict of Interest}

The authors have no potential conflicts of interest to declare. 


\section{References}

Braun, V., \& Clarke, V. (2006). Using thematic analysis in psychology. Qualitative Research in Psychology, 3, 77-101. https://doi.org/10. 1191/1478088706qp063oa

Brown, R. I., Schalock, R. L., \& Brown, I. (2009). Quality of life: Its application to persons with intellectual disabilities and their families-Introduction and overview. Journal of Policy and Practice in Intellectual Disabilities, 6, 2-6. https://doi.org/10.1111/j.17411130.2008.00202.x

Courtenay, K., \& Perera, B. (2020). COVID-19 and people with intellectual disability: Impacts of a pandemic. Irish Journal of Psychological Medicine, 37, 231-236. https://doi.org/10.1017/ipm.2020.45

Embregts, P. J., van den Bogaard, K. J., Frielink, N., Voermans, M. A., Thalen, M., \& Jahoda, A. (2020). A thematic analysis into the experiences of people with a mild intellectual disability during the COVID-19 lockdown period. International Journal of Developmental Disabilities, 1-5. https://doi.org/10. $1080 / 20473869.2020 .1827214$

Maes, B., Geeraert, L., \& Van den Bruel, B. (2000). Developing a model for quality evaluation in residential care for people with intellectual disability. Journal of Intellectual Disability Research, 44, 544-552. https://doi.org/10.1046/j.1365-2788.2000.00266.x

Miles, S., \& Rowe, G. (2004). The Laddering technique. In G.M. Breakwell, (Ed.), Doing social psychology research (pp. 305-343). The British Psychological Society and Blackwell Publishing. https://doi.org/10.1002/9780470776278

Nind, M. (2017). The practical wisdom of inclusive research. Qualitative Research, 17, 278-288. https://doi.org/10.1177/1468794117708123

Reynolds, T. J., \& Gutman, J. (1988). Laddering theory, method, analysis, and interpretation. Journal of Advertising Research, 28, 11-31.

Reynolds, T. J., \& Phillips, J. M. (2009). A review and comparative analysis of laddering research methods: recommendations for quality metrics. In N.K. Malhotra, (Ed.), Review of Marketing Research, (Vol. 5, pp. 130-174). Bingley: Emerald Group Publishing Limited.

Rijksoverheid. (2020). Nieuwe maatregelen tegen verspreiding coronavirus in Nederland. Retrieved from https://www.rijksoverheid.nl/ actueel/nieuws/2020/03/12/nieuwe-maatregelen-tegen-verspreidingcoronavirus-in-nederland
Schalock, R. L. (1996). Quality of life: Application to persons with disabilities (Vol. 2). Washington, D.C.: American Association on Mental Retardation.

Schalock, R. L., Keith, K. D., Verdugo, M. Á., \& Gómez, L. E. (2010). Quality of life model development and use in the field of intellectual disability. In Enhancing the quality of life of people with intellectual disabilities (pp. 17-32). Dordrecht, The Netherlands: Springer.

Schalock, R. L., Verdugo, M. A., Jenaro, C., Wang, M., Wehmeyer, M., Jiancheng, X., \& Lachapelle, Y. (2005). Cross-cultural study of quality of life indicators. American Journal on Mental Retardation, 110, 298-311. https://doi.org/10.1352/0895-8017(2005)110 [298:CSOQOL]2.0.CO;2

Senjam, S. S. (2020). Impact of COVID-19 pandemic on people living with visual disability. Indian Journal of Ophthalmology, 68, 1367-1370. https://doi.org/10.4103/ijo.IJO_1513_20

Tomova, L., Wang, K. L., Thompson, T., Matthews, G. A., Takahashi, A., Tye, K. M., \& Saxe, R. (2020). Acute social isolation evokes midbrain craving responses similar to hunger. Nature Neuroscience, 23, 1597-1605. https://doi.org/10.1038/s41593-02000742-z

Van Slooten, S., Veldhoen, B., Achthoven, W., van Rensch, J., \& van Ratingen, B. (2018). Basisboek customer journey. Een Inleiding in het Vakgebied [Basics-book customer journey. An introduction to the domain]. Groningen/Utrecht, The Netherlands: Noordhoff.

Vereniging Gehandicaptenzorg Nederland. (2020a). Advies bezoekregeling gehandicaptenzorg. Retrieved from https://www.vgn. $\mathrm{nl} /$ nieuws/advies-bezoekregeling-gehandicaptenzorg

Vereniging Gehandicaptenzorg Nederland. (2020b). Lessons learned Gehandicaptenzorg September 2020. Retrieved from https://www. vgn.nl/documenten/lessons-learned-september-2020pdf

World Medical Association. (2013). World Medical Association Declaration of Helsinki: Ethical Principles for Medical Research Involving Human Subjects. Journal of the Americain Medical Association, 310, 2191-2194. https://doi.org/10.1001/jama.2013.281053

Willner, P., Rose, J., Stenfert Kroese, B., Murphy, G. H., Langdon, P. E., Clifford, C., ... Cooper, V. (2020). Effect of the COVID-19 pandemic on the mental health of carers of people with intellectual disabilities. Journal of Applied Research in Intellectual Disabilities., 33, 1523-1533. https://doi.org/10.1111/jar.12811

Zaltman, G. (1996). Metaphorically Speaking. Marketing Research, 8, 13-20. 